\title{
Analisis Perawatan Untuk Mendeteksi Risiko Kegagalan Komponen Pada Excavator 390D
}

\author{
Armin Darmawan ${ }^{1}$, Amrin Rapi ${ }^{2}$, Syafrillah $\mathrm{Ali}^{3}$
}

\begin{abstract}
This study is concerned with maintenance on a heavy equipment excavator 390D series HE4019, one of the main tools used to support the process of nickel production. Major constraint in using this tool is an insufficiently planned maintenance such that the tool affected operational and production process of nickel. Failure mode and effect analysis (FMEA) method is used to identify the risks of failure of critical components on the performance of the unit. Based on risk priority number (RPN), three critical components are found as leading causes of unit downtime. These are stick cylinder (RPN 288), fuel filter (RPN 280) and oil pan (RPN 240), respectively. Mean time between failure $(M T B F)$ scores of stick cylinder, fuel filter and oil pan are 1,288.91 hours, 334.04 hours and 1,455.77 hours, respectively. Each of making rod of the cylinder covered, periodically flushing the fuel tank and taking on a warning sign on the couplers and coating the gasket with an additional layer during installation, in the meantime, are proposed as preventive maintenance for each the three critical components.
\end{abstract}

Keywords. preventive maintenance, corrective maintenance, FMEA, MTBF

\begin{abstract}
Abstrak.Penelitian ini mengkaji tentang studi perawatan pada alat berat excavator $390 D$ seri HE4019, yang merupakan alat utama dalam mendukung proses produksi nikel. Kendala utama dalam penggunaan alat ini yaitu pola perawatan yang kurang terencana dengan baik sehingga memengaruhi operasional dan proses produksi nikel. Analisis perawatan dilakukan dengan metode failure mode and effect analysis (FMEA) dalam mengidentifikasi komponen kritis terhadap kinerja unit. Hasilnya menunjukkan bahwa terdapat tiga komponen kritis penyebab downtime unit berdasarkan peringkat dari nilai Risk Priority Number (RPN).Nilai RPN untuk stickcylinder,penyaring bahan bakar,danoil pan sebesar 288, 280, dan 240. Nilai mean time between failure (MTBF) stick cylinder adalah 1.288,91 jam dengan kegiatan perawatan pencegahannya memasang lapisan penutup pada rod cylinder. MTBF penyaring bahan bakar 334,04 jam, dengan flushing fuel tank secara berkala dan memasang sign peringatan pada kopler. MTBF pada oil pan 1.455,77 jam dengan melapisi gasket dengan lapisan tambahan saat pemasangan.
\end{abstract}

Kata kunci. preventive maintenance, corrective maintenance, FMEA, MTBF

\section{Pendahuluan}

Dunia industri akhir-akhir ini telah mengalami ekselerasi peningkatan kemampuan yang

\footnotetext{
1 Armin Darmawan, Program Studi Teknik Industri Universitas Hasanuddin, Jl. Perintis Kemerdekaan Km.10 Makassar, 90245 (email: darmawanarmin@gmail.com)

${ }^{1}$ Amrin Rapi, Program Studi Teknik Industri Universitas Hasanuddin, Jl. Perintis Kemerdekaan Km.10 Makassar, 90245 (email: amrin_rapi@yahoo.com)

${ }^{1}$ Syafrillah Ali, Program Studi Teknik Industri Universitas Hasanuddin, Jl. Perintis Kemerdekaan Km.10 Makassar, 90245 (email: syafrillah_ali@yahoo.com)
}

Diajukan: 21-07-2016 Disetujui: 10-12-2016 didorong atas dasar kompetisi yang semakin ketat. Peningatan efektivitas dan efisiensi pada industri pertambangan. Salah satunya menuntut adanya peningkatan tingkat ketersediaan peralatan untuk mendukung proses produksi. Untuk mendukung tingkat ketersediaan mesin dan peralatan, perancangan kegiatan perawatan mutlak dibutuhkan karena mesin dan peralatan produksi sangat rawan dengan timbulnya kerusakan. Terjadinya kerusakan dapat mengakibatkan gangguan proses produksi dan keselamatan tenaga kerja juga terancam, dimana keseluruhannya mempengaruhi produktivitas perusahaan.

Salah satu usaha perbaikan pada industri dilihat dari segi peralatan adalah meningkatkan utilisasi peralatan yang ada seoptimal mungkin. Utilisasi dari peralatan yang ada pada rata-rata 
industri manufaktur sekitar setengah kemampuan mesin yang sesungguhnya. Akibatnya, banyak ditemukan permasalahan pada suatu perusahaan bahwa kontribusi terbesar dari total biaya produksi bersumber dari biaya pelaksanaan pemeliharaan peralatan, baik secara langsung maupun tidak langsung (Betrianis, 2005).

PT X merupakan perusahaan yang bergerak dalam pertambangan nikel di Sorowako. Dalam menghasilkan produksi nikel yang baik dengan jumlah yang banyak, diperlukan pula berbagai peralatan. Salah satunya adalah excavator. Keandalan dan ketersediaan excavator ini dapat mempengaruhi kelancaran dari proses produksi nikel. Dalam proses mendapatkan material ore yang nantinya akan dijadikan nikel matte, kadang tidak sesuai dengan perencanaan awal yang disebabkan oleh produktifitas excavator tidak berada pada standar yang diharapkan. Banyak faktor yang mempengaruhi hal tersebut misalnya bucket rusak, silinder dan hose pecah, masalah lubrikasi, dan lain-lain. Hal tersebut dapat mengganggu rencana produksi yang telah ditetapkan. Untuk menjaga kondisi agar excavator tersebut tetap dalam keadaan andal dilakukan proses perawatan yang terjadwal.

Tabel 1. Frekuensi kerusakan unit excavator

\begin{tabular}{ccc}
\hline $\begin{array}{c}\text { No Seri } \\
\text { Excavator }\end{array}$ & $\begin{array}{c}\text { Frekuensi } \\
\text { Kerusakan }\end{array}$ & $\begin{array}{c}\text { Downtime } \\
\text { (jam) }\end{array}$ \\
\hline HE4019 & 129 & 1156,91 \\
HE4020 & 124 & 890,62 \\
HE4021 & 128 & 1087,5 \\
HE4022 & 40 & 239,58 \\
HE4023 & 33 & 369,25 \\
HE4024 & 26 & 234,31 \\
HEC401 & 60 & 297,76 \\
HEC402 & 47 & 332,83 \\
\hline Sumber:Equipment Maint. Dept PT TU, 2015
\end{tabular}

Terdapat 8 unit excavator yang digunakan. Enam unit didatangkan dari PT TU (seri HE4019, HE4020, HE4021, HE4022, HE4023, HE4024), sedang dua unit sisanya adalah rental excavator dari PT TU juga (seri HEC401 dan HEC402). Semua kegiatan perawatan pada alat berat tersebut ditangani langsung oleh PT TU. Rangkuman kerusakan alat berat tersebut selama satu tahun terakhir (Periode 26 Juli 2014 - 8 Juli 2015), ditampilkan pada Tabel 1.

Berdasarkan data di atas terlihat bahwa seri HE4019 merupakan excavator dengan frekuensi kerusakan tinggi (129 kali) dan nilai downtime paling besar (1.156,91 jam). Oleh karena itu, excavator HE4019 dipilih untuk dijadikan fokus penelitian.

Berdasarkan hal tersebut, perusahaan dapat menentukan komponen yang diprioritaskan untuk diberikan solusinya secara bertahap, sehingga dapat meminimalkan terjadinya kerusakan unit, diantaranya dengan memberikan rekomendasi perawatan yang dapat dilakukan baik secara preventive maupun corrective. Sehubungan dengan hal tersebut, penelitian ini mengkaji rancangan perawatan untuk mendeteksi risiko kegagalan komponen pada Excavator 390D.

\section{Metodologi}

Failure mode and effect analysis (FMEA) digunakan pada perancangan teknik rekayasa, seperti perancangan, pengidentifikasian, dan pengeliminasian kegagalan system, baik yang telah terjadi maupun yang potensial. FMEA awalnya diimplementasikan oleh NASA pada tahun 1963 untuk kebutuhan keandalan sistem. Kemudian diadopsi oleh Ford Motor. Sejak itu FMEA menjadi alat yang relevan untuk analisis risiko dan keandalan sistem industry secara luas seperti pada otomotif, nuklir, konstruksi, dan lainnya (Shafiee \& Dinmohammadi, 2014).

Prosedur dalam langkah-langkah FMEA dapat dibagi dalam beberapa tahapan sebagai berikut ini (Pillay \& Wang, 2003): (1) menggambarkan flow proses dan melakukan peninjauan terhadap proses, bila sistem bekerja secara baik pada tiap lini proses; (2) mengidentifikasi potential failure mode (mode kegagalan potensial) pada proses; (3) membuat daftar potential effect (pengaruh potensial) dari tiap mode kegagalan pada setiap lini dan pengaruhnya; (4) menentukan peringkat severity (S) untuk masing-masing mode kegagalan yang terjadi dengan skala tingkatan 10 ; (5) menentukan peringkat occurance $(\mathrm{O})$ untuk masing-masing mode kegagalan dengan skala tingkatan 10; (6) menentukan peringkat detection (D) untuk masing-masing mode kegagalan dan/atau akibat yang terjadi dngan skala tingkatan 10; (7) menghitung nilai Risk Priority Number (RPN) untuk tiap cacat; (8) membuat prioritas 
mode kegagalan berdasarkan nilai RPN untuk dilakukan tindakan perbaikan, dan (9) menyusun rekomendasi perbaikan.

Pada kajian penelitian ini dilakukan identifikasi pada komponen-komponen kritis yang menjadi penyebab utama terjadinya risiko kegagalan operasi pada Excavator 390D dengan menggunakan pendekatan metode failure mode and effect analysis (FMEA). Data frekuensi kerusakan komponen pada Excavator 390D merupakan data dasar yang digunakan dalam menentukan prioritas komponen kritis yang dikaji melalu perhitungan Risk Priority Number (RPN).

Selanjutnya dilakukan perhitungan mean time between failure (MTBF), peluang kerusakan komponen (probability density function), digunakan software Weibull untuk menentukan jenis distribusi kegagalan komponen. Menghitung keandalan dan laju kegagalan sehingga didapatkan nlai keandalan komponen. $M T B F$ merupakan waktu yang paling tepat untuk dilakukan maintenance, sebelum terjadi kerusakan terhadap komponen-komponen kritis yang menjadi prioritas kajian berdasarkan output dari FMEA. Dari hasil pehitungan MTBF ini dapat digunakan untuk penjadwalan maintenance yang akurat terhadap komponen-komponen kritis dari output FMEA.

\section{Laju Kegagalan}

Laju kegagalan $(\lambda)$ adalah banyaknya kegagalan per satuan waktu. Laju kegagalan dapat dinyatakan sebagai perbandingan antara banyaknya kegagalan yang terjadi selama selang waktu tertentu dengan total waktu operasi komponen, subsistem, atau sistem.

Laju kegagalan dinyatakan dengan persamaan:

$$
\lambda(t)=\frac{f(t)}{R(t)}
$$

Dimana:

$f(t)=$ fungsi padat peluang kegagalan selama jangka waktu proses $(p d f)$

$R(t)=$ total waktu operasi.

Laju kegagalan suatu komponen dapat digambarkan dengan sebuah kurva bak mandi (bath tube curve) dengan variabel waktu sebagai laju kegagalan dari komponen (sistem).

Model dari probabilitas kegagalan komponen suatu alat dapat dicocokkan dengan distribusi statistik. Dalam analisa keandalan ada beberapa distribusi statistik yang umum digunakan. Jika laju kerusakan dari sistem independent umumdan karakteristiklain secara pengoperasiannya, maka yang lebih tepat digunakan adalah distribusi eksponensial. Distribusi ini berhubungan dengan laju kerusakan konstan. Jika laju kerusakannya meningkat seiring dengan bertambahnya umur sistem, maka distribusi yang digunakan adalah distribusi normal dan Weibull (Iksan, 2010).

MTBF adalah waktu rata-rata antar kegagalan atau rata-rata waktu beroperasinya komponen, subsistem, atau sistem tanpa mengalami kegagalan. MTBF diperoleh dari hasil bagi antara total waktu operasi dengan jumlah kegagalan dalam periode waktu operasi tersebut.

MTBF dapat dinyatakan dengan rumus :

$M T B F=\frac{\text { Total waktu operasi }}{\text { Frekuensi pemeliharaan }}$

\section{Penentuan Distribusi Umur Komponen Kritis}

Untuk menganalisis distribusi waktu kejadian kerusakan atau kegagalan komponen. umumnya model distribusi statistik yang banyak digunakan berbentuk distribusi kontinyu seperti distribusi normal, log-normal, exponential, dan Weibull (Priyanta, 2000). Penjelasan mengenai distribusi statistik tiap jenis distribusi,diuraikan sebagai berikut:

1. Distribusi normal

Fungsi padat peluang (probability density function) pada distribusi normal adalah:

$$
f(t)=\frac{1}{\sigma \sqrt{2 \pi}} \exp \left[-\frac{1}{2}\left(\frac{t-\mu}{\sigma}\right)^{2}\right]
$$

Dimana:

$\mu=$ rata-rata (mean)

$\sigma=$ standar deviasi

Jika distribusi waktu antar kegagalan suatu komponen, subsistem, atau sistem mengikuti distribusi normal, maka:

a. fungsi keandalan distribusi normal ádalah:

$$
R(t)=\int_{t}^{\infty} \frac{1}{\sigma \sqrt{2 \pi}} \exp \left[-\frac{1}{2}\left(\frac{t-\mu}{\sigma}\right)^{2}\right]
$$

b. Laju kegagalan distribusi normal adalah:

$$
\lambda(t)=\frac{\exp \left[-(t-\mu)^{2} / 2 \sigma^{2}\right]}{\int_{t}^{\infty} \exp \left[-(t-\mu)^{2} / 2 \sigma^{2}\right] d t}
$$

c. $\mathrm{MTBF}=\mu$ 
2. Distribusi log-normal

Waktu antar kegagalan dari suatu komponen, subsistem, atau sistem mengikuti distribusi $\log$-normal, bila $y=\ln (t)$, mengikuti distribusi normal dengan rata-rata $t_{o}$ dan varians $s$. Fungsi padat peluang (probability density function) distribusi log-normal adalah:

$$
f(t)=\frac{1}{t . s \sqrt{2 \pi}} \exp \left[-\frac{1}{2}\left(\frac{\ln t-t_{o}}{s}\right)^{2}\right]
$$

Jika distribusi waktu antar kegagalan suatu komponen, subsistem, atau sistem mengikuti distribusi log-normal, maka:

a. Fungsi keandalan distribusi log-normal adalah:

$$
R(t)=1-\phi\left[\frac{1}{s} \ln \frac{t}{t_{o}}\right]
$$

b. Failure rate secara umum:

$$
\lambda(t)=\frac{f(t)}{R(t)}
$$

$$
\text { c. } \mathrm{MTBF}=\exp \left(t_{o}+\left(0,5 \times s^{2}\right)\right.
$$

3. Distribusi eksponensial

Fungsi padat peluang (probability density function) distribusi Eksponensial adalah:

$$
f(t)=\lambda e^{-\lambda(t-\gamma)}, \mathrm{t}>0, \lambda>0, \mathrm{t} \geq \gamma
$$

Dimana:

$\lambda=$ laju kegagalan (failure rate)

$\gamma=$ parameter lokasi (location parameter)

Jika distribusi waktu antar kegagalan suatu komponen, subsistem, atau sistem mengikuti distribusi Eksponensial, maka :

a. Keandalan distribusi eksponensial adalah:

$$
R(t)=e^{-\lambda(t-\gamma)}
$$

b. Failure rate secara umum:

$$
\lambda(\mathrm{t})=\lambda
$$

c. $\mathrm{MTBF}=1 / \lambda$

4. Distribusi Weibull

Fungsi padat peluang (probability density function) distribusi Weibull adalah:

$$
f(t)=\frac{\beta}{\eta}\left(\frac{t-\gamma}{\eta}\right)^{\beta-1} \exp \left[-\left(\frac{t-\gamma}{\eta}\right)^{\beta}\right]
$$

Dimana:

$\eta=$ scale parameter, $\eta>0$

$\beta=$ shape parameter, $\beta>0$ $\gamma=$ location parameter.

Jika distribusi waktu antar kegagalan suatu komponen, subsistem, atau sistem mengikuti distribusi Weibull, maka :

a. Fungsi keandalan distribusi Weibull adalah:

$$
R(t)=\exp \left[-\left(\frac{t-\gamma}{\eta}\right)^{\beta}\right]
$$

b. Laju kegagalan distribusi Weibull adalah:

$$
\lambda(t)=\frac{\beta}{\eta}\left(\frac{t-\gamma}{\eta}\right)^{\beta-1}
$$

$$
\text { c. } \mathrm{MTBF}=\gamma+\eta \Gamma(1 / \beta+1)
$$

Dengan penggunaan kedua pendekatan diatas didapatkan rancangan perawatan yaitu penentuan komponen kritis, jadwal maintenance, dan rekomendasi perbaikan terhadap komponenkomponen kritis.

\section{HASIL DAN PEMBAHASAN}

Berdasarkan data jenis kerusakan yang terdapat pada masing-masing komponen maka hasil yang didapatkan seperti yang dapat dilihat pada Tabel 2 dimana terdapat 37 komponen. Dari 37 komponen tersebut dilakukan analisis berdasarkan pendekatan FMEA. Dalam kajian ini pendekatan FMEA mendukung dalam penentuan skala prioritas terhadap komponen yang kritis. Sehingga dapat membantu dalam pengambilan keputusan dengan dasar yang kuat terkait dengan komponen mana yang memerlukan tindakan pembenahan segera. Pendekatan FMEA meninjau dari 3 hal yaitu severity, occurrence, dan detection yang menghasilkan Risk Priority Number(RPN). Penentuan prioritas komponen kritis dipilih berdasarkan urutan jumlah RPN tertinggi.

Nilai RPN yang semakin tinggi menunjukkan bahwa tingkat risiko yang dapat ditimbulkan masuk dalam kategori risiko tinggi artinya risiko ini bila terjadi dapat mengakibatkan dampak yang besar, frekuensi kejadiannya sering terjadi, dan sulit untuk mendeteksi secara dini potensi risiko tersebut. Komponen dengan nilai RPN tertinggi menunjukkan bahwa komponen tersebut menjadi prioritas pertama untuk dilakukan penggantian, perbaikan, dan perawatan (Ibrahim \& El-Nafaty, 2016). Berdasarkan Tabel 2, terdapat tiga komponen yang memiliki nilai RPN yang sangat tinggi dibanding komponen lainnya. Maka dari 
Tabel 2. Ranking berdasarkan FMEA untuk tiap komponen Excavator 390D

\begin{tabular}{|c|c|c|c|c|c|}
\hline No & Komponen & Mode Kegagalan & Potensi Efek Kegagalan & RPN & Rank \\
\hline 1 & Stick cylinder & Kebocoran cylinder & Tenaga hidrolik berkurang & 288 & 1 \\
\hline 2 & Fuel Filter & $\begin{array}{l}\text { Penyumbatan pada } \\
\text { sirkulasi bahan bakar }\end{array}$ & Engine tidak dapat running & 280 & 2 \\
\hline 3 & Oil pan & Oli engine habis & Komponen engine panas & 240 & 3 \\
\hline 4 & Engine & Kebocoran & Kehabisan oil engine & 144 & 4 \\
\hline 5 & Water separator & $\begin{array}{l}\text { Penyumbatan pada } \\
\text { sirkulasi bahan bakar }\end{array}$ & Pembakaran tidak maksimal & 144 & 4 \\
\hline 6 & Pressure sensor & Intermittent & Engine pressure indicator on & 140 & 5 \\
\hline 7 & Starting motor & Motor tidak dapat berputar & Engine tidak dapat running & 128 & 6 \\
\hline 8 & Water pump & Malfunction & Engine Overheating & 128 & 6 \\
\hline 9 & Hose coolant & Kebocoran hose & $\begin{array}{l}\text { Engine overheating karena coolant } \\
\text { pendingin habis }\end{array}$ & 128 & 6 \\
\hline 10 & Harness & Intermittent & $\begin{array}{l}\text { Informasi elektronik ke kontrol tidak ada } \\
\text { sehingga kerusakan tidak terdeteksi dini }\end{array}$ & 128 & 6 \\
\hline 11 & Hose hydraulic & Kebocoran & $\begin{array}{l}\text { Excavator kehilangan tenaga penggerak } \\
\text { implement }\end{array}$ & 128 & 6 \\
\hline 12 & Joystick & Pergerakan kaku & $\begin{array}{l}\text { Alat kerja excavator tidak dapat } \\
\text { digerakkan }\end{array}$ & 128 & 6 \\
\hline 13 & Fuel lines & Kebocoran fuel lines & Fuel habis & 128 & 6 \\
\hline 14 & Lamp & Padam & Penerangan dimalam hari terganggu, & 128 & 6 \\
\hline 15 & Alternator & Pengisian baterai buruk & Baterai lowbat/rusak & 125 & 7 \\
\hline 16 & Grease injector & Penyumbatan & $\begin{array}{l}\text { Tidak ada pelumasan grease pada } \\
\text { komponen tertentu }\end{array}$ & 120 & 8 \\
\hline 17 & Bucket & Penyok/ terlekuk & Volume tampung bucket berkurang & 120 & 8 \\
\hline 18 & Bucket & Sobek pada sisi bucket & Pemindahan material tidak efektif & 120 & 8 \\
\hline 19 & Grease pump & Aus, Tersumbat & $\begin{array}{l}\text { Tidak ada pelumasan grease pada } \\
\text { excavator }\end{array}$ & 100 & 9 \\
\hline 20 & $\begin{array}{l}\text { Coolant flow } \\
\text { sensor }\end{array}$ & Stuck & $\begin{array}{l}\text { Indikator on di dashboard (Active code } \\
\text { warning menyala) }\end{array}$ & 96 & 10 \\
\hline 21 & Swing gear & Aus & Pergerakan memutar excavator sulit & 96 & 10 \\
\hline 22 & Fuel lines & $\begin{array}{l}\text { Penyumbatan pada } \\
\text { sirkulasi bahan bakar }\end{array}$ & Engine sulit running & 96 & 10 \\
\hline 23 & Tip Bucket & Tumpul & $\begin{array}{l}\text { Pengerukan tanah/bebatuan sulit } \\
\text { dilakukan }\end{array}$ & 96 & 10 \\
\hline 24 & Lock Pin bucket & Patah & Pin bucket terlepas & 80 & 11 \\
\hline 25 & Tip Bucket & $\begin{array}{l}\text { Terlepas dari adapter } \\
\text { bucket }\end{array}$ & Tidak dapat menyayat tanah/bebatuan & 80 & 11 \\
\hline 26 & Side Protector & Terlepas & Kerusakan bucket & 60 & 12 \\
\hline 27 & Side Protector & Aus & $\begin{array}{l}\text { Pengerukan tanah/bebatuan sulit } \\
\text { dilakukan }\end{array}$ & 60 & 12 \\
\hline 28 & Edge Protector & Patah & Mempercepat kerusakan bucket & 60 & 12 \\
\hline 29 & Edge Protector & Aus & $\begin{array}{l}\text { Pengerukan tanah/bebatuan sulit } \\
\text { dilakukan }\end{array}$ & 60 & 12 \\
\hline 30 & Grease hose & Hose bocor & $\begin{array}{l}\text { Gangguan pelumasan grease pada } \\
\text { komponen }\end{array}$ & 60 & 12 \\
\hline 31 & Front glass & Pecah & $\begin{array}{l}\text { Kabin kemasukan material asing sehingga } \\
\text { operator tidak nyaman }\end{array}$ & 56 & 13 \\
\hline 32 & Wear Plate & Aus & Bucket penyok & 48 & 14 \\
\hline 33 & Adapter & Patah & Pengerukan material berat & 48 & 14 \\
\hline 34 & Glass (rear) & Pecah & $\begin{array}{l}\text { Operator tidak nyaman, Kemasukan debu } \\
\text { air dalam kabin operator }\end{array}$ & 42 & 15 \\
\hline 35 & Grease timer & Tidak berfungsi & $\begin{array}{l}\text { Waktu penginjection grease terganggu } \\
\text { sehingga pelumasan pin kurang baik }\end{array}$ & 36 & 16 \\
\hline 36 & Door gp (hyd clr) & Sulit dibuka, Bengkok & $\begin{array}{l}\text { Pengecekan oli visual sulit, Penggantian } \\
\text { filter hydrolic tidak bisa diakses }\end{array}$ & 32 & 17 \\
\hline 37 & Seal glass & Terlepas & Kabin kemasukan air & 24 & 18 \\
\hline
\end{tabular}

itu dipilih tiga komponen kritis teratas mode, potensi efek dan penyebab kegagalan, beradasarkan RPN dan untuk itu dapat dilihat 
1. Stick cylinder merupakan komponen yang berfungsi untuk menggerakkan lengan bucket excavator. Karena seal wiver sobek dan lip seal fatigue akibatnya tenaga hidrolik berkurang. Oleh karena itu terjadi kebocoran pada stick cylinder.

2. Fuel filter merupakan komponen yang berfungsi untuk menyaring bahan bakar pada proses pembakaran di engine. Mode kegagalan dari komponen ini adalah tersumbatnya sirkulasi bahan bakar dan engine tidak dapat running. Hal ini terjadi karena fuel filter-nya jarang diganti.

3. Oil pan sebagai wadah penampungan engine oil. Dalam hal ini komponen oil pan mengalami kehabisan engine oil, sehingga komponen engine menjadi panas karena kurangnya sirkulasi oli pelumas engine. Hal tersebut disebabkan gasket oil pan kaku atau rusak sehingga bocor.

Keluaran FMEA ini menjadi solusi dalam analisis penentuan komponen kritis. Kemudian dilakukan eksplorasi terhadap ketiga komponen kritis tersebut dengan menghitung distribusi kegagalan dengan pendekatan statistik masingmasing komponen dan menentukan rata-rata waktu operasi antar kegagalan (MTBF).

Berdasarkan hasil pengolahan pada Tabel 3, dapat diperoleh prediksi jam terjadinya kerusakan dalam hal ini adalah MTBF sehingga dapat dilakukan preventive maintenance sebelum kerusakan terjadi. Dengan mengetahui MTBF ini maka dapat membantu dalam penentuan jadwal maintenance yang dapat dilakukan untuk ketiga komponen tersebut.
Tabel 3. Hasil perhitungan MTBF dan distribusi komponen kritis Excavator 390D

\begin{tabular}{clrl}
\hline No & Komponen & $\begin{array}{c}\text { MTBF } \\
\text { (jam) }\end{array}$ & Distribusi \\
\hline $\mathbf{1}$ & Stick cylinder & 1288.91 & Normal \\
$\mathbf{2}$ & Fuel Filter & 334.04 & Weibull \\
$\mathbf{3}$ & Oil pan & 1455.768 & Weibull \\
\hline
\end{tabular}

\section{Preventive dan Corrective Maintenance}

Hasil pengolahan data menunjukkan ketiga komponen kritis diatas merupakan komponen yang apabila masing-masing komponen tersebut mengalami kerusakan maka dapat berakibat pada alat excavator tidak beroperasi. Bila terjadi kebocoran pada stick cylinder, maka excavator tidak bisa beroperasi. Jika hal ini terjadi, maka bucket yang berfungsi untuk mengais material tidak dapat digerakkan. Pressure akan hilang sehingga tenaga hidrolik berkurang. Kebocoran pada stick cylinder juga sulit untuk dideteksi lebih awal, sehingga dibutuhkan modifikasi untuk memantau dan mendeteksi kebocoran lebih dini. Sedang pada fuel filter yang berfungsi menyaring bahan bakar, kegagalan terjadi ketika proses pembakaran di engine. Mode kegagalan pada komponen ini yaitu tersumbatnya sirkulasi bahan bakar, sehingga engine tidak dapat running dan berakibat pada excavator tidak dapat beroperasi. Pada komponen oil pan, mode kegagalan mengalami kehabisan engine oil, sehingga mengakibatkan komponen engine menjadi panas. Hal tersebut disebabkan oleh sirkulasi oli pelumas engine berkurang. Bila tidak dilakukan pengawasan dan pengendalian pada kebocoran

Tabel 4. Preventive dan corrective maintenance komponen kritis excavator 390D

\begin{tabular}{|c|c|c|c|c|c|}
\hline No & Komponen & $\begin{array}{c}\text { MTBF } \\
\text { (jam) }\end{array}$ & $\begin{array}{c}\text { Penyebab } \\
\text { Kegagalan }\end{array}$ & Corrective Maintenance & Preventive Maintenance \\
\hline 1 & Stick cylinder & $1.288,91$ & $\begin{array}{l}\text { Seal wiver sobek } \\
\text { dan lip seal } \\
\text { fatigue }\end{array}$ & $\begin{array}{l}\text { Melakukan rekondisi } \\
\text { stick cylinder }\end{array}$ & $\begin{array}{l}\text { Memasang lapisan penutup } \\
\text { pada rod cylinder }\end{array}$ \\
\hline 2 & Fuel Filter & 334,04 & $\begin{array}{l}\text { Fuel filter jarang } \\
\text { diganti }\end{array}$ & $\begin{array}{l}\text { Memodifikasi fuel tank } \\
\text { dengan menambahkan } \\
\text { pipa setinggi kurang lebih } \\
5 \mathrm{~cm} \text { pada dasar tangki }\end{array}$ & $\begin{array}{l}\text { Flushing fuel tank secara } \\
\text { berkala }\end{array}$ \\
\hline & & & & $\begin{array}{l}\text { Memasang penutup } \\
\text { permanen pada kopler } \\
\text { pengisian }\end{array}$ & $\begin{array}{l}\text { Memasang sign peringatan } \\
\text { pada kopler agar pengisian } \\
\text { selalu dalam kondisi bersih }\end{array}$ \\
\hline 3 & Oil pan & $1.455,77$ & $\begin{array}{l}\text { Gasket oil pan } \\
\text { kaku atau rusak } \\
\text { sehingga bocor }\end{array}$ & $\begin{array}{l}\text { Menutup sisi oil pan } \\
\text { yang bocor dengan } \\
\text { silicon paste }\end{array}$ & $\begin{array}{l}\text { Melapisi gasket dengan lapisan } \\
\text { tambahan saat pemasangan }\end{array}$ \\
\hline
\end{tabular}


engine oil dapat mengakibatkan kegagalan operasi mesin dan mengalami stuck.

\section{SIMPULAN}

Artikel kajian maintenance ini berfokus pada penentuan komponen yang menjadi komponen kritis, jadwal maintenance, dan rekomendasi tindakan maintenance.

Hasil penerapan metode FMEA diperoleh komponen kritis dengan masing-masing nilai RPN ketiga tertinggi yaitu stick cylinder, fuel filter, dan oil pan. Penyebab kegagalan ketiga komponen yang dapat dideteksi lebih cepat, yaitu: pada stick cylinder disebabkan oleh seal wiver robek dan lip seal mengalami puncak kelelahan, pada fuel filter disebabkan oleh frekuensi penggantian yang jarang, dan pada oil pan disebabkan oleh kerusakan gasket oil pan.

Jadwal maintenanceuntuk ketiga komponen tersebut masing-masing: stick cylinder dengan MTBF $1.288,91 \mathrm{jam}$, fuel filter (334,04 jam), dan oil pan $(1.455,77 \mathrm{jam})$.

Beberapa tindakan preventive dan corrective maintenance yang dapat dilakukan untuk mencegah tingkat risiko kegagalan yang lebih tinggi. Pada stick cylinder dengan melakukan rekondisi stick cylinder (corrective maintenance) dan memasang lapisan penutup pada stick cylinder (preventive maintenance). Pada fuel filter dengan memodifikasi fuel tank dengan menambahkan pipa setinggi $5 \mathrm{~cm}$ dari dasar tangki atau dengan memasang penutup permanen pada kopler pengisian (corrective maintenance) dan melakukan flushing fuel tank secara berkala. Dan pada oil pan untuk tindakan corrective maintenance yaitu melapisi gasket dengan lapisan tambahan saat pemasangan.

Salah satu hal yang perlu dieksplorasi selanjutnya dari hasil kajian ini yaitu menghitung kebutuhan biaya maintenance untuk ketiga komponen tersebut. Selain itu, dari ketiga komponen tersebut terdapat 2 komponen yang memiliki jadwal maintenance hampir sama. Hal ini perlu dipertimbangkan apabila jadwalnya dibuat bersamaan seperti apa pengaruhnya terhadap penjadwalan terutama terkait dengan biaya.

\section{DAFTAR PUSTAKA}

Ibrahim, A.; El-Nafaty, A.U. 2016. "Assesment of the realibility of fractionator column of Kaduana refinery using failure mode effect and critically analysis". American Journal of Engineering Research, Vol. 5 (2), pp. $101-108$.

Iksan. 2010. "Menentukan interval perawatan pencegahan padamesin stripping di PT Aditama Raya Farmindo dengan metode age replacement". Agritek, Vol. 5 (1), pp. $61-71$.

Pillay, A.; Wang, J. 2003. "Modified failure mode effect and analysis using approximate reasoning". Reliability Engineering System and Safety, Vol. 79 (1), pp. 69 - 85.

Priyanta, D. 2000. Keandalan dan Perawatan. Surabaya: Teknik Perkapalan ITS

Shafiee, M.; Dinmohammadi, F. 2014. "An FMEA-based risk assesment approach for wind turbine systems: A comparative study of onshore and offshore". Energies, Vol. 7 (2), pp. 619-642.

Sodikin, I. 2010. "Analisis penentuan waktu perawatan dan jumlah persediaan suku cadang rantai garu yang optimal”. Jurnal Teknologi, Vol. 3 (1), pp. $44-52$. 